\title{
Quality of emergency medical care in Gondar University Referral Hospital, Northwest Ethiopia: a survey of patients' perspectives
}

Belaynew Wasie Taye ${ }^{1,4^{*}}$, Mensur Ousman Yassin ${ }^{2}$ and Zemene Tigabu Kebede ${ }^{3}$

\begin{abstract}
Background: Ethiopia has fairly good coverage but very low utilization of health care services. Emergency medical care services require fast, correct and curious services to clients as they present with acute problems. In Ethiopia and Gondar in particular, the quality of emergency medical care has not been studied. The main aim of this study was to assess the disease profile and patients' satisfaction in Gondar University Referral Hospital (GURH).

Methods: A facility based cross-sectional study was conducted among patients visiting GURH for emergency care. Ethical clearance was obtained from the Institutional Review Board of University of Gondar. Patients were selected by systematic random sampling, using patient flow list in the day and night emergency services. Data were collected using a standard Press Ganey questionnaire by BSc health science graduates. Data were entered in to Epi Info 3.5.3 software and exported to SPSS version 20.0 for windows for analysis.

Results: A total of 963 patients (response rate $=96.8 \%$ ) were studied. The mean $(+$ s.d.) age of patients was 28.4 (+17.9) years. The overall satisfaction using the mean score indicates that 498 (51.7\%) 95\%Cl: (48.4\% - 54.9\%) were satisfied with the service, the providers and the facility suitability whereas $465(48.3 \%) 95 \% \mathrm{Cl}$ : (45.1\%- 51.6\%) were not satisfied. Seven hundred and six (73.3\%) 95\%Cl: 70.4\%-76.1\%, patients reported that they have been discriminated or treated badly during the service provision in the hospital. OPD site visited $(p<0.0001)$, visiting days of the week $(P<0.049)$, medical condition on arrival $(P<0.0001)$, degree of confidence in the hospital $(A O R=1.9$, $95 \% \mathrm{Cl}: 1.1,3.1$ ), reported discrimination/bad treatment of patients with service ( $\mathrm{AOR}=0.4,95 \% \mathrm{Cl}: 0.2,0.7$ ), were significantly associated determinants of patient satisfaction.

Conclusions: Non-communicable disease emergencies like injuries and cardiovascular diseases are common. There is a low level of patient satisfaction related to lack of confidence in the hospital for treatment, discrimination towards patient care, and under and delayed treatment of patients who were not in serious medical conditions. Hospitals shall prepare themselves to address the increasing challenge of non-communicable disease emergencies. It is important to revise the service delivery in the emergency department to improve staff courtesy and politeness, commitment, reduce discrimination and bad treatment and proper triage of emergencies at all points of care to increase patient satisfaction giving emphasis to earlier working days.
\end{abstract}

Keywords: Emergency care, Quality, Patient satisfaction, Gondar, Northwest Ethiopia

\footnotetext{
* Correspondence: bewassie@yahoo.com

'Department of Epidemiology and Biostatistics, Bahir Dar University, Bahir Dar, Ethiopia

${ }^{4}$ Operational Research Advisor, Amhara Regional Health Bureau, Bahir Dar, Ethiopia

Full list of author information is available at the end of the article
}

\section{Biomed Central}

(c) 2014 Taye et al.; licensee BioMed Central Ltd. This is an open access article distributed under the terms of the Creative Commons Attribution License (http://creativecommons.org/licenses/by/2.0), which permits unrestricted use, distribution, and reproduction in any medium, provided the original work is properly cited. 


\section{Background}

Ethiopia has good health coverage with about $89 \%$ physical access or reachability, but unacceptably low utilization at 29\%. Cognizant of this fact, the Ethiopian Federal Ministry of Health has stated that universal access to emergency service will be provided to all citizens $[1,2]$. The low rates of utilization of care entail the absence of basic service capacity standards, affordability, weak referral systems and quality of services [1].

With a growing focus on disease control with emergency care and non-communicable diseases, $[3,4]$ medical emergency care is becoming a medical specialty in many developed countries while managed sporadically in the developing countries [5]. The major reasons for emergency OPD visits are gastroenteritis/diarrhea, lower respiratory infections, malaria, ischemic heart disease, septicemia, and injuries [6,7]. Public violence among men and domestic violence to women that are commonly seen in young people are also important causes of emergency department visits [8].

Currently in Ethiopia, cardiovascular admissions- notably due to ischemic heart disease- have risen in the last two decades and it is reported that there are no referral facilities within $100 \mathrm{~km}$ [9]. The median waiting time for patients is about $8 \mathrm{~min}$ (from 0 to $3 \mathrm{~h} 59 \mathrm{~min}$ ), and the median therapeutic time was $56 \mathrm{~min}$ (from $5 \mathrm{~min}$ to $16 \mathrm{~h} 19 \mathrm{~min}$ ) [7].

Persons who experience pain and other symptoms as life threatening [10], men and older patients, persons who are triaged for the more advanced illnesses, those nearer to the hospital, patients with psychiatric disorders, and asthmatics visit emergency clinics more frequently than the normal population [11-14]. In some cases, patients report more often at the beginning of the week than on the weekends [7]. Perceived urgency of disease, a younger population, females, non-attended patients during the day time, a longer duration of the illness, and non-traumatic injuries are the group of patients who visit the emergency OPD for a non-urgent care [15].

Patient satisfaction in emergency care is a challenging experience.

The patients seek high quality care but there is an absence of well-organized facilities and experienced, dedicated staff and this leads to patient dissatisfaction. This dissatisfaction is a major problem in emergency medical care [16]. The level of satisfaction in emergency care ranges from as low as $2 \%$ in Pakistan [17] and 63\% in Iran [18] to as high as $99.5 \%$ in United Sates [16].

The major reasons for the dissatisfaction are interpersonal communications [16], system problems including inadequately equipped facilities, no budget allocates for emergency departments and a lack of critical supplies which are needed in emergency situations [17]. Other determinants of satisfaction are physicians' and nurses' communication with patients, security guards' courtesy and communication, the mean waiting time, and the occurrence of unscheduled events which delayed care $[18,19]$.

Classification of patients' degree of problems for priority care, and training of staff on emergency care improved patient care and ensured better patient satisfaction [20,21].

Quality of care is a corner stone in an organizations' goal. Currently, the Ministry of Health is expanding emergency care to the needy populations. The Gondar University Referral Hospital has a goal of improving satisfaction of patients [22]. There is lack of evidence that assesses the quality of care in emergency units among hospitals in the Amhara Regional State. This study assessed the disease profile, level of patient satisfaction and determinants of quality emergency care in a tertiary hospital in Northwest Ethiopia.

\section{Methods}

\section{Study design}

This was a hospital based cross-sectional study that assessed disease profile and quality of service among patients presenting to emergency department of GURH.

\section{Setting}

The study was conducted in GURH. This is a tertiary teaching hospital serving about 5 million people. The hospital has 518 beds and sees between 350 to 400 patients each day and between 100-120 emergency patients. The hospital has four emergency suites with a triage unit for distribution. It is staffed by about 270 nurses and 150 physicians. All adult cases pass through the triage unit of the hospital before seeing doctors except for children who go directly to the pediatric clinic.

\section{Study population}

The study population was all cases reporting to the emergency department with any emergency problem and presenting to all the OPDs. Patients presenting to the follow up clinic or for regular services and women presenting to the hospital for normal delivery services were excluded.

\section{Sample size and sampling techniques}

The sample size was determined using single population proportion formula: $\mathrm{n}=\frac{\mathrm{Z}_{\alpha / 2}^{2} \times \mathrm{p}(1-\mathrm{p})}{\mathrm{W}^{2}}$

The assumptions were, $\mathrm{P}=63 \%$ (the proportion of good quality of emergency medical care measure by patient satisfaction from Iranian study [18]; $Z=1.96$, (the value of standard normal distribution at $95 \%$ confidence level, $\mathrm{w}=3 \%$, (marginal error) giving a sample size of 995 patients.

The study participants were selected by a systematic random sampling technique where the first case was identified among the 1-4 lists of patients presenting first at the start date of data collection using a lottery 
method. Thereafter, every $4^{\text {th }}$ subject at each section of the hospital's emergency departments was interviewed. Patients coming in both during the day and night hours were included. In the case where a patient was in distress and could not be interviewed, the care takers of the patients were consulted. The severity of patients was determined subjectively by clinicians.

\section{Study variables}

The outcome variable was quality of emergency care measured in terms of patient satisfaction. The explanatory variables included socio-demographic characteristics, the OPD sites, the day of the week, medical condition, perception about the hospital care, history of admission, time of arrival, the patient's perception of service, and courtesy of hospital staff.

\section{Definitions}

Medical emergency was defined as a condition wherein patients presented with acute illness /accident within $48 \mathrm{hrs}$ and chronic patients with acute exacerbations within $48 \mathrm{hrs}$, unstable patients- such as patients with grossly abnormal vital signs or unconsciousness, and metabolic disturbances. Quality of emergency care was perceived satisfaction of care by emergency patients. Patient satisfaction was defined as the feelings of pleasure or disappointment as a result of a rendered service with a comparison of the performance of the institution's care against the expectations of the patient [23]. Patient satisfaction was measured by a Likert scale of 20 questions and was graded as very dissatisfied, dissatisfied, fair/indifferent, satisfied and very satisfied. Those scoring the mean or below were considered as dissatisfied while a score above the mean was labeled as satisfied.

\section{Data collection instrument and procedures}

Data were collected by a standard modified 20 items Press Ganey questionnaire developed in English, translated to Amharic and back translated to English by different person to check for consistency. A pre-test was conducted on 20 patients in the Gondar Polyclinic before the main and the instrument was amended accordingly.

An exit interview was conducted after patients were examined and treated. To avoid social desirability bias, data collection took place in a private area. If a patient was unconscious or in distress, care takers gave consent and were interviewed.

Data collectors were graduate nurses, health officers and environmental health technicians who were not working in the emergency department. Training was provided on the data collection techniques and utilization of the study tool for one day. There was daily supervision of data collection by the investigators. The completed questionnaires were checked for completeness and accuracy every day. Confidentiality of information was assured through use of the anonymous questionnaire. A code was used to identify the patient to avoid repeat interviews.

\section{Statistical analysis}

Data were entered in to the Epi Info Version 3.5.3 statistical package by data entry clerks, then cleaned and exported to SPSS version 20.0 for windows for analysis by investigators. Descriptive statistics were calculated to present sociodemographic characteristics, disease profiles, and levels of satisfaction. Bivariate and multiple logistic regression analyses were used to determine the association of different factors with satisfaction. P-values less than 0.05 or $95 \%$ CI not including the null value were considered as statistically significant.

\section{Ethical issues}

Ethical clearance was obtained from Institutional Review Board of the University of Gondar. A letter of permission was obtained from the chief executive officer of the hospital. Data collection resumed after informed consent was obtained from each patient or guardian if aged less than 18 years. For patients who were unable to give consent due to age or serious illness, caretakers and guardians gave the consent and were interviewed. To ensure confidentiality, an anonymous questionnaire was used and the interviews were conducted in a private area. All patients, care takers or guardians had the right to withdraw at any point during data collection without any consequences to the quality of service.

\section{Results}

\section{Socio-demographic characteristics of patients}

A total of 963 patients were included in the study with a response rate of $96.8 \%$. The other $3.2 \%$ participants were either non-response or excluded due to incomplete. The mean age of patients was $28.4(+17.9)$ years. Children under the age of 15 years accounted for 20.6 percent of the participants with $9.2 \%$ under the age of five years. Elderly patients accounted for $4.6 \%$. There were comparable numbers of males (48.5\%) 95\%CI: $45.5 \%-51.7 \%$, and females (51.5\%) 95\%CI: 48.3\%-54.5\%. Nearly two-thirds (60.7\%) 95\%CI: $57.7 \%-63.9 \%$, of the patients were from rural areas and $271(28.1 \%)$ were housewives by occupation followed by students comprising $21.3 \%$ of all patients. Most of the patients (81.4\%), 95\%CI: $80.1 \%-86.4 \%$, arrived during the morning (AM) hours (Table 1).

\section{Profile of diseases and general medical condition of patients} The most common diagnosis in the emergency OPD was injury seen in 140 (14.5\%), 95\%CI: 12.4\%-16.8\%, patients. Gastrointestinal disorders took the next greater share with 
Table 1 Socio-demographic characteristics of patients at the emergency departments in Gondar University Referral Hospital, Northwest Ethiopia, May 2012

\begin{tabular}{lll}
\hline Characteristic & $\begin{array}{c}\text { Number } \\
\text { of patients }\end{array}$ & Percent \\
\hline
\end{tabular}

Age of patient

$<5$

5-14

$15-24$

25-34

35-44

45-54

55-64

$65+$

Sex of patient

Male

Female

Residence of patient

Rural

Urban

Occupation of patient $(n=837)$

Merchant

Farmer

Student

Housewife

Government employee

Daily laborer

Other

Days of visit

Monday

Tuesday

Wednesday

Thursday

Friday

Saturday

Sunday

OPD site visited

Medicine

Obstetrics/gynecology

Pediatrics

Surgery

Oral health, psychiatry, eye

Time of arrival at OPD/emergency unit

Morning

Afternoon/evening
9.2

11.4

25.9

21.9

11.2

10.6

5.2

4.6

48.5

51.5

60.7

39.3

3.5

18.9

21.3

28.1

6.0

3.7

5.3

11.9

20.2

19.7

16.4

11.7

10.0

10.0

43.2

13.0

17.2

24.1

2.5

81.4

18.6
126 (13.1\%), 95\%CI: 10.9\%-15.5\%, patients followed by respiratory diseases 115 (11.9\%), 95\%CI: 9.4\%-14.6\%, and obstetric/gynecologic emergencies (11.0\%), 95\%CI: 8.9\%-13\%. Cardiovascular problems were also significant and were observed in $55(5.7 \%)$ of the patients. Cancers of any form were also observed in 39 (4\%) of the patients (Figure 1).

At the time of arrival at the emergency OPD, 422 (43.8\%), 95\%CI: $40.6 \%-46.8 \%$, patients were very sick or in critical condition while a similar proportion, 416 (43.2\%), 95\%CI: $40.1 \%-46.2 \%$, were moderately sick. A total of 125 (13.0\%), 95\%CI: $10.7 \%-15.2 \%$, of the patients were in good condition. Five hundred eight (52.8\%) patients were managed in the emergency unit while the rest were either admitted, 452 (46.9\%) to the respective wards or referred, $3(0.3 \%)$ to another facility. The patient's stays in the emergency department ranged from 1-2 hours $(29.3 \%), 95 \% \mathrm{CI}$ : $25.2 \%-33.7 \%$, to as long as 24 hours or more (17.5\%) $95 \%$ CI: $13.8 \%-21.1 \%$. The mean duration of the stay in the emergency department was 16.9 hours (Table 2).

\section{Health service related characteristics of patients}

One hundred sixty-nine (17.6\%), 95\%CI: 15.4\%-20.0\%, patients cancelled their emergency room visit while there was a perceived reason. The main reasons for cancelling their visit were a lack of money, 92 (54.4\%), and in 67 (39.7\%) of them because of a mix of reasons including not trusting accessibility of service, family problems and a preference for traditional medicine.

Regarding confidence in getting good service from the hospital, 582(60.4\%) were very confident, 268 (27.8\%) confident, 40 (4.2\%) were somewhat confident, and 73 (7.6\%) were not confident at all (Table 3 ).

A large number, 706 (73.3\%) 95\%CI: 70.4\%-76.1\%, of patients reported that they had been discriminated against or treated badly during the provision of service in the hospital. The major source of discrimination and bad treatment were failure of the health worker to discuss the expenses for treatments, 203 (28.7\%), unequal handling or treatment by the health workers, 126 (17.8\%), inability to get treatment, $88(12.5 \%)$, not spending enough time with patient, $60(8.5 \%)$, not listening to the patient $52(7.4 \%)$, looking down on the patient, 50 (7.1\%), and the health worker talking unkindly to the patient, 7 (1.0\%) (Figure 2).

\section{Overall quality of care/patient satisfaction Reliability analysis}

To check for the internal consistency of the 20-item satisfaction measurement tool, we did reliability analysis. The overall Cronbach's alpha value was 0.88 reflecting a very high consistency of instrument-tomeasure the satisfaction. The inter-item correlation was also low (all well below 0.6) showing that each item 


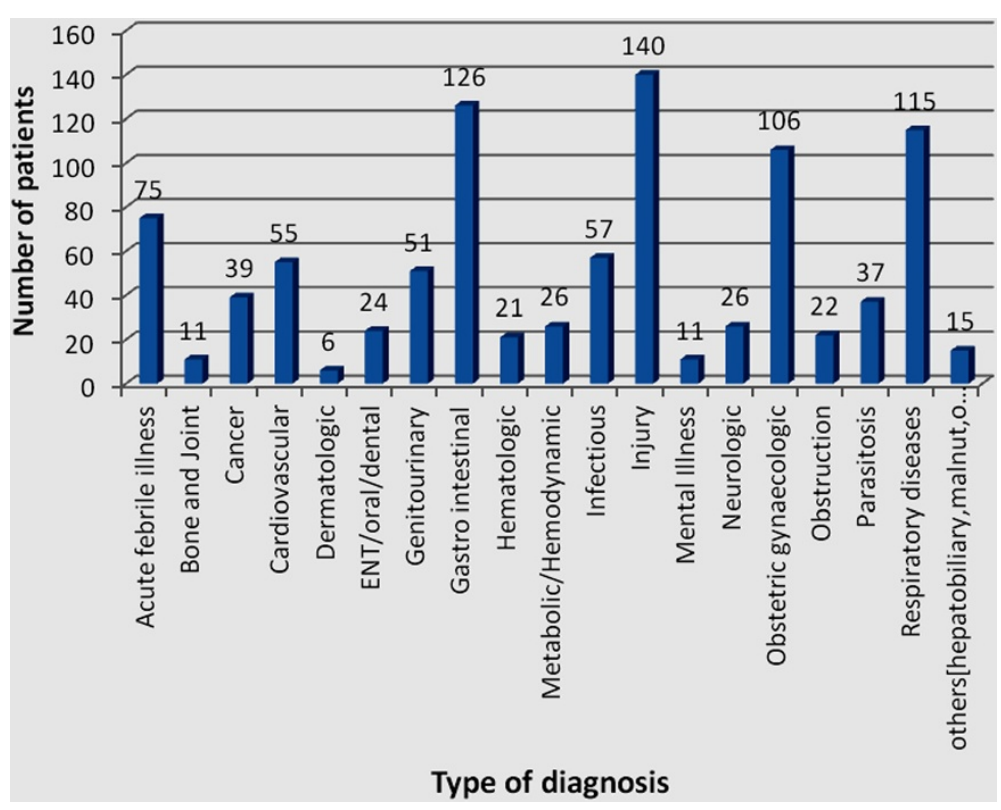

Figure 1 Disease profile of patients at emergency departments in Gondar University Referral Hospital, May 2012.

was measuring distinct characteristics of patient satisfaction. On top of the overall alpha value, the value for each of the 20 items was also high (Table 4).

The overall satisfaction using the mean score indicated that 498 (51.7\%) 95\%CI: (48.4\% - 54.9\%) were satisfied with the service, the providers and the facility suitability whereas 465(48.3\%) 95\%CI: (45.1\%- 51.6\%) were dissatisfied. Assessing the clients' satisfaction for each item, $36.3 \%$ of the clients were dissatisfied or indifferent to the courtesy of staff in the registration area while $63.7 \%$ were either satisfied or very satisfied. In about two-thirds $(64.2 \%)$ of clients, the information provided about medication was not satisfying and ranked fair or below. The degree to which the care providers talked to the patient using words which the patients could understand was high at 74.2\% (Table 5).

\section{Determinants of patient satisfaction on emergency medical care}

In the multiple logistic regression analysis using backward stepwise method, the OPD site visited was significantly associated with level of satisfaction $(\mathrm{p}<0.0001)$. Individuals who visited OPD 2 were 1.6 times more likely to be satisfied with the service as compared to those served at OPD $5(\mathrm{AOR}=1.6,95 \% \mathrm{CI}: 1.1,2.4)$. Patients who visited OPD 3 were 3.4 times more likely to be satisfied with the emergency service when compared to those visiting OPD $5(\mathrm{AOR}=3.4,95 \% \mathrm{CI}: 2.1,5.8)$.

The visiting days also had an effect on satisfaction of patient with emergency care provided $(\mathrm{p}<0.05)$. Patients who arrived on Monday were less likely to be satisfied when compared to those visiting on Sundays, even though this turned out to be non-statistically significant in the final model. Patients who came to OPD on Thursday $(\mathrm{AOR}=1.7,95 \% \mathrm{CI}: 1.1,3.0)$ and Friday $(\mathrm{AOR}=1.9,95 \% \mathrm{CI}$ : $1.1,3.4)$ were more likely to be satisfied when compared to their counterparts arriving on Sunday.

The medical condition on arrival was a predictor for patient satisfaction at the emergency department $(\mathrm{p}<0.0001)$. Patients who were very sick on clinical assessment on their arrival were 3.6 times more likely to be satisfied when compared to those with good conditions $(\mathrm{AOR}=3.6$, $95 \% \mathrm{CI}: 2.3,5.5)$ on arrival and patients with moderate condition were 1.6 times more likely to be satisfied with the service $(A O R=1.6,95 \% C I: 1.1,2.5)$. Patients very confident with the service provided were nearly twice more likely to be satisfied with emergency service (AOR = 1.9, 95\%CI: 1.1, 3.1).

Another vital determinant of patient satisfaction was perception of being discriminated against by health care providers. Those who felt that they were discriminated against at some care provision point were 2.5 times less likely to be satisfied with the service $(\mathrm{AOR}=0.4,95 \% \mathrm{CI}$ : $0.2,0.7)$. Patient satisfaction was not significantly associated with waiting time, residence, gender, age or other variables (Table 6).

\section{Discussion}

The study assessed the quality of health service at the emergency units of Gondar University Referral Hospital using a 20-item patient satisfaction questionnaire. Many of the patients presented from Monday to Wednesday accounted to more than $60 \%$ of visitors in all days of the week. Many of the patients reported at the beginning of the week similar to the situation in other studies [7]. 
Table 2 Medical conditions of patients at emergency departments in Gondar University Referral Hospital, Northwest Ethiopia, May 2012

\begin{tabular}{|c|c|c|}
\hline Medical characteristic & Number of patients & Percent \\
\hline \multicolumn{3}{|l|}{ Presence of any past illness } \\
\hline Yes & 580 & 60.2 \\
\hline No & 383 & 39.8 \\
\hline \multicolumn{3}{|c|}{ General condition of patient on arrival } \\
\hline Good condition & 125 & 13.0 \\
\hline Somewhat sick & 416 & 43.2 \\
\hline Very sick & 422 & 43.8 \\
\hline \multicolumn{3}{|l|}{ Subsequent management decision } \\
\hline Managed in emergency room & 508 & 52.8 \\
\hline Admitted & 452 & 46.9 \\
\hline Referred & 3 & 0.3 \\
\hline \multicolumn{3}{|l|}{ Emergency visit before } \\
\hline Yes & 538 & 55.9 \\
\hline No & 424 & 44.0 \\
\hline I don't know & 1 & 0.1 \\
\hline \multicolumn{3}{|c|}{ Duration of stay in emergency department $(n=508)$} \\
\hline $1-2$ hours & 149 & 29.3 \\
\hline 3-6 hours & 124 & 24.4 \\
\hline 7-12 hours & 61 & 12.0 \\
\hline 13-21 hours & 85 & 16.7 \\
\hline$>/=24$ hours & 89 & 17.5 \\
\hline \multicolumn{3}{|l|}{ History of admission to hospital } \\
\hline Yes & 104 & 10.8 \\
\hline No & 857 & 89.0 \\
\hline I don't know & 2 & 0.2 \\
\hline \multicolumn{3}{|l|}{ Previous chronic illness } \\
\hline No & 672 & 69.8 \\
\hline Yes & 291 & 30.2 \\
\hline High blood pressure & 42 & 4.4 \\
\hline Cardiac problem & 116 & 12.0 \\
\hline Cancer & 10 & 1.0 \\
\hline Diabetes & 25 & 2.6 \\
\hline Anxiety & 70 & 7.3 \\
\hline Obesity & 3 & 0.3 \\
\hline Asthma & 25 & 2.6 \\
\hline
\end{tabular}

Injuries were the leading cause of emergency OPD visits with $14.5 \%$ of all visitors. This is in line with studies in different countries [6-8]. The higher number of injuries in emergency OPD in this study was due to significant road traffic and vehicle crashes that caused many patients to visit the emergency department. Public violence among men and domestic violence with women was also a common cause of injuries [8]. Other unusual problems observed
Table 3 Health service related characteristics of patients at emergency departments in Gondar University Referral Hospital, Northwest Ethiopia, May 2012

\begin{tabular}{lcc}
\hline Health service related character & Number of patients & Percent \\
\hline $\begin{array}{l}\text { Cancelled hospital visit last time } \\
\text { Yes }\end{array}$ & 769 & \\
No & 2 & 17.6 \\
Don't remember & & 82.2 \\
Reason for cancelling visit before (n= 169) & 0.2 \\
Lack of money & 92 & \\
Other reason & 67 & 54.4 \\
I don't know & 10 & 39.7 \\
Degree of confidence to get good service in the future & 5.9 \\
Very confident & 582 & 60.4 \\
Confident & 268 & 27.8 \\
Somewhat confident & 40 & 4.2 \\
Not confident at all & 73 & 7.6 \\
Believed discriminated & & \\
No & 257 & 26.7 \\
Yes & 706 & 73.3 \\
\hline
\end{tabular}

in the emergency diagnoses were non-communicable diseases including cancer, cardiovascular diseases, hematologic, mental illness, metabolic and neurologic disorders and these contributed to a total of $18.2 \%$. This confirms the threat of a double burden of infectious and non-communicable disease that will be a challenge to the health care system in Ethiopia [2,24]. Cardiovascular disorders alone contribute $5.7 \%$ of emergency visits which supports previous evidence to the rise of the problems and signals that the emergency care at hospitals and referral system has to be revised based on the current prevailing conditions [9].

Discrimination and bad treatment of patients was found to be high $(73.3 \%)$ in this study mainly due to poor interpersonal communication of patients' problems, their treatment and/or cost of care. This tells clinicians that investigation and prescriptions are not the only needs of patients and all the concerns should be addressed in an understandable way. Other studies also identified that physician and nurse communications with patients were important determinants of satisfaction [18].

The reliability analysis for the patient satisfaction measurement items resulted in an overall Cronbach's alpha score of 0.88 . This tells that the tool is consistent for measuring the patient satisfaction. Moreover, the inter- item correlation coefficients were all less than 0.05 showing the items are mutually exclusive and measure different issues.

The level of patient satisfaction of $51.7 \%$ with the emergency service at the hospital is very low. This figure is lower than studies in Iran and other countries $[16,18]$ where there 


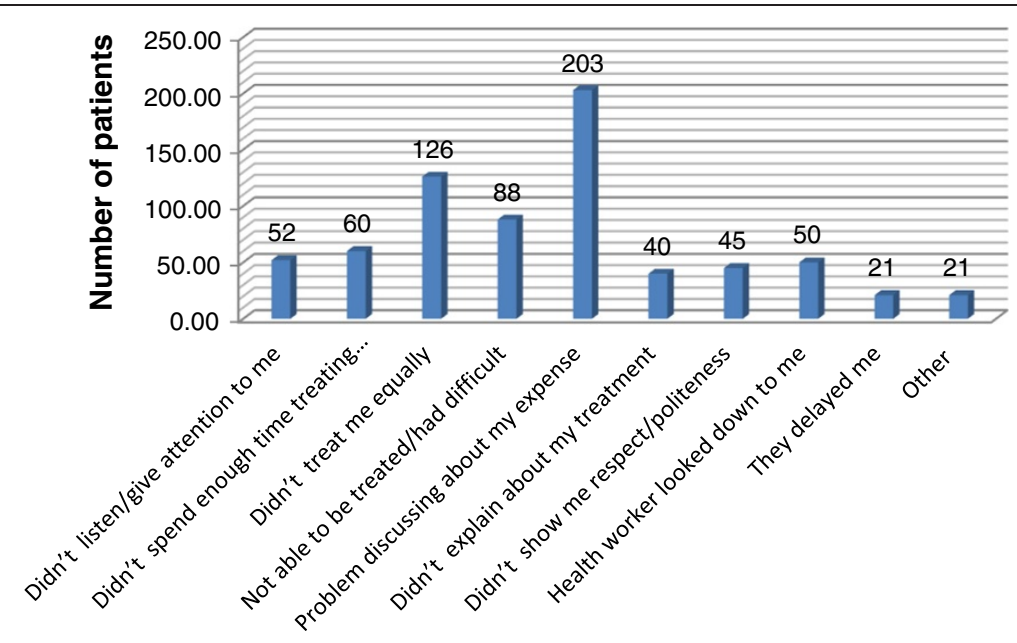

Means of discrimination/bad treatment

Figure 2 Means of discrimination/bad treatment among patients at emergency departments in Gondar University Referral Hospital, May 2012.

is $63 \%$ or more satisfaction with emergency care. The reason may be due to the presence of a specialized emergency care service in the later that provided a better care for patients. It is however, much higher than the findings from Pakistan [17]. The very high discrepancy is due to the fact that the Pakistan study additionally considered the ambulance service call for emergency conditions to reach health facilities that might have overestimated the dissatisfaction. This will have a negative effect on health care utilization on top of a very low

Table 4 Reliability analysis of the 20 patient satisfaction measurement items among patients at emergency departments in Gondar University Referral Hospital, Northwest Ethiopia, May 2012

\begin{tabular}{|c|c|c|c|}
\hline Item & Mean score & Standard deviation & Cronbach's a \\
\hline Courtesy of staff in the registration area & 3.55 & 1.09 & 0.877 \\
\hline Comfort and pleasantness of the waiting area & 3.31 & 0.99 & 0.875 \\
\hline Comfort and pleasantness during examination & 3.40 & 1.01 & 0.873 \\
\hline Friendliness/courtesy of the nurse & 3.60 & 0.91 & 0.873 \\
\hline Concern the nurse showed for doing medical orders & 3.68 & 0.87 & 0.876 \\
\hline Courtesy of security staff & 3.49 & 0.95 & 0.876 \\
\hline Courtesy of staff who transfer the patients & 3.50 & 0.97 & 0.876 \\
\hline Length of wait before going to an exam room & 3.35 & 1.17 & 0.877 \\
\hline Friendliness/courtesy of the care provider & 3.73 & 0.84 & 0.872 \\
\hline Explanations the care provider gave you about your condition & 3.02 & 1.11 & 0.875 \\
\hline Concern the care provider showed for your questions or worries & 3.35 & 1.02 & 0.871 \\
\hline Care provider's efforts to include you in decisions about your treatment & 3.06 & 1.09 & 0.872 \\
\hline Information the care provider gave you about medications & 2.94 & 1.08 & 0.876 \\
\hline Instructions the care provider gave you about follow-up care & 3.01 & 1.05 & 0.875 \\
\hline Degree to which care provider talked with you using words you could understand & 3.83 & 0.84 & 0.875 \\
\hline Amount of time the care provider spent with you & 3.58 & 0.92 & 0.872 \\
\hline Frequency of being visit by physicians & 3.46 & 0.99 & 0.872 \\
\hline Overall cheerfulness of hospital practice & 3.50 & .99 & 0.874 \\
\hline Overall cleanliness of hospital practice & 3.40 & 1.05 & 0.881 \\
\hline Likelihood of your recommending the practice to others & 3.81 & 1.00 & 0.875 \\
\hline Total items score & 3.43 & 1.00 & 0.88 \\
\hline
\end{tabular}


Table $\mathbf{5}$ Levels of satisfaction based on $\mathbf{2 0}$ measurement items among patients visiting emergency departments in Gondar University Referral Hospital, Northwest Ethiopia, May 2012

\begin{tabular}{|c|c|c|c|c|c|}
\hline \multirow[t]{2}{*}{ Item } & \multicolumn{5}{|c|}{ Level of satisfaction } \\
\hline & $\begin{array}{c}\text { Very unsatisfied } \\
\text { No. (\%) }\end{array}$ & $\begin{array}{c}\text { Unsatisfied } \\
\text { No. (\%) }\end{array}$ & $\begin{array}{c}\text { Fair } \\
\text { No. (\%) }\end{array}$ & $\begin{array}{c}\text { Satisfied } \\
\text { No. (\%) }\end{array}$ & $\begin{array}{c}\text { Very satisfied } \\
\text { No. (\%) }\end{array}$ \\
\hline Courtesy of staff in the registration area & $62(6.4)$ & $112(11.6)$ & $176(18.3)$ & $464(48.2)$ & $149(15.5)$ \\
\hline Comfort and pleasantness of the waiting area & $35(3.6)$ & $185(19.2)$ & $269(27.9)$ & $398(41.3)$ & $76(7.9)$ \\
\hline Comfort and pleasantness during examination & $27(2.8)$ & $192(19.9)$ & $215(22.3)$ & $429(44.5)$ & $100(10.4)$ \\
\hline Friendliness/courtesy of the nurse & $32(3.3)$ & $79(8.2)$ & $240(24.9)$ & $501(52.0)$ & $111(11.5)$ \\
\hline Concern the nurse showed for doing medical orders & $20(2.1)$ & $75(7.8)$ & $224(23.3)$ & $520(54.0)$ & $124(12.9)$ \\
\hline Courtesy of security staff & $38(3.9)$ & $105(10.9)$ & $258(26.8)$ & $468(48.6)$ & $94(9.8)$ \\
\hline Courtesy of staff who transfer the patients & $29(3.0)$ & $116(12.0)$ & $289(30.0)$ & $399(41.4)$ & $130(13.5)$ \\
\hline Length of wait before going to an exam room & $78(8.1)$ & $175(18.2)$ & 189 (19.6) & $378(39.3)$ & $143(14.8)$ \\
\hline Friendliness/courtesy of the care provider & $18(1.9)$ & $66(6.9)$ & $196(20.4)$ & $560(58.2)$ & $123(12.8)$ \\
\hline Explanations the care provider gave you about your condition & $99(10.3)$ & $229(23.8)$ & $249(25.9)$ & $325(33.7)$ & $61(6.3)$ \\
\hline Concern the care provider showed for your questions or worries & $40(4.2)$ & $175(18.2)$ & $254(26.4)$ & $394(40.9)$ & $100(10.4)$ \\
\hline Care provider's efforts to include you in decisions about your treatment & $77(8.0)$ & $242(25.1)$ & $257(26.7)$ & $316(32.8)$ & $71(7.4)$ \\
\hline Information the care provider gave you about medications & $102(10.6)$ & $247(25.6)$ & $270(28.0)$ & $299(31.0)$ & $45(4.7)$ \\
\hline Instructions the care provider gave you about follow-up care & $76(7.9)$ & $246(25.5)$ & $286(29.7)$ & $301(31.3)$ & $54(5.6)$ \\
\hline $\begin{array}{l}\text { Degree to which care provider talked with you using } \\
\text { words you could understand }\end{array}$ & $19(2.0)$ & $40(4.2)$ & $202(21.0)$ & $523(54.3)$ & $179(18.6)$ \\
\hline Amount of time the care provider spent with you & $24(2.5)$ & $97(10.1)$ & $258(26.8)$ & $465(48.3)$ & $119(12.4)$ \\
\hline Frequency of being visit by physicians & $38(3.9)$ & $131(13.6)$ & $253(26.3)$ & $431(44.8)$ & $110(11.4)$ \\
\hline Overall cheerfulness of hospital practice & $44(4.6)$ & $101(10.5)$ & $261(27.1)$ & $442(45.9)$ & $115(11.9)$ \\
\hline Overall cleanliness of hospital practice & $51(5.3)$ & $159(16.5)$ & $209(21.7)$ & $442(45.9)$ & $102(10.6)$ \\
\hline Likelihood of your recommending the practice to others. & $42(4.4)$ & $62(6.4)$ & $156(16.2)$ & $477(49.5)$ & $226(23.5)$ \\
\hline
\end{tabular}

rate. It is vital to save lives of patients by improving the suitability and quality of care to patients.

Patients who were served in OBGY and Surgery departments were 1.6 and 3.44 times more likely to be satisfied as compared to those visiting other departments respectively. This may be related to the nature of intervention that solves the patients' concerns and observed illness via surgical and other procedures.

Patients who arrived on Mondays were less likely to be satisfied as compared to those arriving Sunday. This is due to the overstretched OPD by the large numbers of regular and emergency patients that makes hard to adequately treat all patients satisfactorily.

Patients with serious medical condition were nearly 3.6 times more likely to be satisfied with the service as compared to those with good condition. This is probably due to the better attention and more time given to critical patients than those in good condition. Senior physicians also are more likely to be consulted for this group of patients leading to better handling. Critical patients' are also given priority at the gate and may not be subjected to bad treatment or discrimination. This is because of the lack of classification of patients on arrival and provide care accordingly that would improve patient handling [20,21].

Having felt discriminated is a negative determinant of satisfaction in the emergency care. Those who felt that they were badly treated were 2.5 times less likely to be satisfied with the service than their counterparts.

\section{Study limitations}

The study participants' selection depended on those reporting to emergency departments and might have dealt with more critical cases. The study involved interview of patients and care takers in case of critical conditions to the patient and this might result in minor differences in response regarding quality of care of the patient. As this is a cross-sectional study, the pattern of all disease could not have been viewd over time. The patient satisfaction might have been influenced by surgical interventions done to some in need against those medically treated.

\section{Conclusions}

Injuries and non-communicable diseases emergency as cardiovascular emergencies are very common among patients in Northwest Ethiopia. 
Table 6 Logistic Regression analysis of factors associated with patient satisfaction among emergency outpatient departments in GURH, Northwest Ethiopia; May 2012

\begin{tabular}{|c|c|c|c|c|c|}
\hline \multirow{2}{*}{ Character } & \multicolumn{2}{|c|}{ Level of satisfaction } & \multicolumn{2}{|c|}{ OR (95\% C.I.) } & \multirow{2}{*}{ P-value } \\
\hline & Satisfied & Not satisfied & Crude & Adjusted & \\
\hline \multicolumn{5}{|l|}{ OPD site visited } & $<0.0001$ \\
\hline Medicine & 201 & 215 & $1.3(0.9,1.8)$ & $1.3(0.9,1.2)$ & .164 \\
\hline Surgery & 126 & 106 & $1.6(1.1,2.4)$ & $1.6(1.1,2.4)$ & .039 \\
\hline OBGY & 87 & 38 & $3.1(1.9,5.0)$ & $3.4(2.1,5.8)$ & $<0.0001$ \\
\hline Oral health, psychiatry & 13 & 11 & $1.6(0.7,3.7)$ & $1.5(0.6,3.8)$ & .379 \\
\hline Pediatrics & 71 & 95 & 1 & 1 & \\
\hline \multicolumn{5}{|l|}{ Visiting days of the week } & .049 \\
\hline Monday & 50 & 65 & $0.9(0.5,1.5)$ & $.9(0.5,1.5)$ & .587 \\
\hline Tuesday & 103 & 92 & $1.3(0.8,2.1)$ & $1.4(0.8,2.3)$ & .231 \\
\hline Wednesday & 97 & 93 & $1.2(0.7,1.9)$ & $1.4(0.8,2.3)$ & .223 \\
\hline Thursday & 91 & 67 & $1.5(0.9,2.6)$ & $1.7(1.1,3.0)$ & .044 \\
\hline Friday & 64 & 49 & $1.5(0.9,2.6)$ & $1.9(1.1,3.4)$ & .027 \\
\hline Saturday & 48 & 48 & $1.1(0.6,2.0)$ & $1.2(0.6,2.1)$ & .636 \\
\hline Sunday & 45 & 51 & 1 & 1 & \\
\hline \multicolumn{5}{|l|}{ Medical condition on arrival } & $<0.0001$ \\
\hline Good condition & 45 & 80 & 1 & 1 & \\
\hline Somewhat sick & 185 & 231 & $1.4(0.9,2.2)$ & $1.6(1.1,2.5)$ & .030 \\
\hline Very sick & 268 & 154 & $3.1(2.0,4.7)$ & $3.6(2.3,5.5)$ & $<.0001$ \\
\hline \multicolumn{5}{|c|}{ Degree of confidence on the hospital } & $<0.0001$ \\
\hline Very confident & 342 & 240 & $1.7(1.1,2.8)$ & $1.9(1.1,3.1)$ & .019 \\
\hline Confident & 109 & 159 & $0.8(0.5,1.4)$ & $0.95(0.6,1.7)$ & .853 \\
\hline Somewhat confident & 14 & 26 & $0.7(0.3,1.5)$ & $0.6(0.3,1.3)$ & .200 \\
\hline Not confident at all & 33 & 40 & 1 & 1 & \\
\hline \multicolumn{6}{|c|}{ Reported discrimination in service } \\
\hline No discrimination & 172 & 85 & 1 & 1 & \multirow{2}{*}{$<0.0001$} \\
\hline Felt discriminated & 326 & 380 & $0.4(0.3,0.6)$ & $0.4(0.2,0.7)$ & \\
\hline
\end{tabular}

There is low level of patient satisfaction in the emergency department. The sources of dissatisfaction were lack of courtesy of staff, physical discomfort, unavailability of drugs, under treatment of patient not in serious medical condition, and discrimination and bad treatment of patients.

Type of OPD visited, days of visit, medical condition on arrival, confidence on the hospital to get good treatment, and presence of discrimination/bad treatment of patients were statistically significantly associated determinants of patient satisfaction.

Hospitals shall prepare themselves to address the increasing challenge of non-communicable disease emergencies that would result in longer duration of stay, high cost of care, and increasing hospital mortality. There has to be a mechanism to motivate staff to handle patients of all categories of severity properly and equally without discrimination and bad treatment. There is a need for evidence-based interventions in emergency care services in physician care, nursing care, courtesy of staff, physical comfort, and equal treatment to improve satisfaction. Hospitals shall improve patient services to narrow the gap between health coverage and utilization.

\section{Competing interests}

This research was sponsored by the University of Gondar; however the sponsorship has no influence or linkage to the findings or publication of this manuscript. The authors declare that there are no competing interests.

Authors' contributions

BWT, MOY, and ZTK were involved in the concept, design, data collection and analysis. All authors read and approved the final manuscript.

\section{Acknowledgements}

The authors would like to thank University of Gondar for funding the research. The authors also want to forward their gratitude to the patients, care-takers and data collectors for their valuable time and responses. 


\section{Author details}

${ }^{1}$ Department of Epidemiology and Biostatistics, Bahir Dar University, Bahir Dar, Ethiopia. ²Department of Surgery, University of Gondar, Gondar, Ethiopia. ${ }^{3}$ Department of Paediatrics, University of Gondar, Gondar, Ethiopia.

${ }^{4}$ Operational Research Advisor, Amhara Regional Health Bureau, Bahir Dar, Ethiopia.

Received: 20 December 2012 Accepted: 22 January 2014

Published: 23 January 2014

\section{References}

1. World health organization(WHO) Regional Office for Africa: WHO Country Cooperation Strategy 2008-2011. Ethiopia: WHO; 2009.

2. Ethiopia Federal Ministry of Health (FMOHE): Health and Health Related Indicators, Health Planning and programming department, 2009/10(2002 EFY). Addis Ababa, Ethiopia: Federal Ministry of Health; 2010.

3. Razzak J, Kellermann AL: Emergency medical care in developing countries: is it worthwhile? Bull World Health Organ 2002, 80(11):900-905.

4. World Health Organization, WHO: World Health Report. Geneva: Bulletin of World Health Organization; 2003:19-21.

5. Sakr M, Wardrope J: Casualty, accident and emergency, or emergency medicine, the evolution. J Accid Emerg Med 2000, 17:314-319.

6. Hyder A, Morrow RH: Applying burden of disease methods in developing countries: a case study from Pakistan. Am J Public Health 2000, 90(8):1235-1240

7. Traoré A, Ouédraogo HZ, Sondo B, Guissou IP: Medical emergencies in the Yalgado Ouedraogo national hospital of Ouagadougou: patients' profile and assessment of care practices. Sante 2002, 12(3):307-312.

8. Hofner M, Python NV, Martin E, Gervasoni JP, Graz B, Yersin B: Prevalence of victims of violence admitted to an emergency department. Emerg Med J 2005, 22:481-485.

9. Levine AC, Presser DZ, Rosborough S, Ghebreyesus TA, Davis MA: Understanding barriers to emergency care in low-income countries: view from the front line. Prehospital Disast Med 2007, 22(5):467-470.

10. Olsson M, Hansagi $\mathrm{H}$ : Repeated use of the emergency department: qualitative study of the patient's perspective. Emerg Med J 2001 18:430-434.

11. Gabriella DG, Rossella A, Luciana A, Paolo M, Angelillo IF, The Collaborative Research Group: Characteristics of patients returning to emergency departments in Naples, Italy. BMC Health Serv Res 2008, 8(97). doi:10.1186/ 1472-6963-8-97.

12. Moore L, Deehan A, Seed $P$, Jones R: Characteristics of frequent attenders in an emergency department: analysis of 1-year attendance data. Emerg Med J 2009, 26:263-267.

13. Al-dawood KM: Pattern and risk factors associated with hospital Emergency visits among schoolboys with bronchial asthm a in al-khobar. Ann saudi med 2002, 22(1-2):29-33.

14. Jacques B, Chris RT, Brie W: Medical emergency department utilization patterns among uninsured patients with psychiatric disorders. Psychiatr Serv 2008, 59(7):808-811.

15. Claudia P, Gianluca R, Italo FA: Paediatric utilization of an emergency department in Italy. Eur J Public Health 2006, 16(5):565-569.

16. Aaron W, Christopher JL, Daniel AH, et al: Postal survey methodology to assess patient satisfaction in a suburban emergency medical services system: an observational study. BMC Emerg Med 2007, 7(5). doi:10.1186/ 1471-227X-7-5.

17. Junaid A, Adnan AH, Tasleem A, Mubashir K, Uzma RK: Assessing emergency medical care in low income countries: a pilot study from Pakistan. BMC Emerg Med 2008, 8(8). doi:10.1186/1471-227X-8-8.

18. Hassan S, Changiz G, Shaker S, et al: Emergency department patient satisfaction survey in Imam Reza Hospital, Tabriz, Iran. Int J Emerg Ment Med 2011, 4(2). doi: 10.1186/1865-1380-1-2.

19. Marleen S, Peter PG, Danielle RMT, van der Wal G, Cordula W: The nature and causes of unintended events reported at ten emergency departments. BMC Emerg Med 2009, 9(16). doi:10.1186/1471-227X-9-16.

20. Ivor W, Hyacinth EH, Shamir OC, Eric WW, Jean WJ: Emergency department physician training in Jamaica: a national public hospital survey. BMC Emerg Med 2008, 8(11). doi:10.1186/1471-227X-8-11.

21. Jarmo $K$, Johanna $K$, Juho $M$, et al: Impact of the $A B C D E$ triage on the number of patient visits to the emergency department. BMC Emerg Med 2010, 10(12). doi:10.1186/1471-227X-10-12
22. Gondar University Hospital: Strategic plan of the Gondar University hospital 2011-2015. Gondar: Gondar University Hospital; 2011.

23. Zairi M: Managing customer satisfaction: a best practice perspective. TQM Magazine 2000, 12(6):389-94.

24. Central Statistics Agency, ORC Macro: Ethiopian demographic and health survey 2005. Addis Ababa: Central Statistics Agency; 2005.

doi:10.1186/1471-227X-14-2

Cite this article as: Taye et al:: Quality of emergency medical care in Gondar University Referral Hospital, Northwest Ethiopia: a survey of patients' perspectives. BMC Emergency Medicine 2014 14:2.

\section{Submit your next manuscript to BioMed Central and take full advantage of:}

- Convenient online submission

- Thorough peer review

- No space constraints or color figure charges

- Immediate publication on acceptance

- Inclusion in PubMed, CAS, Scopus and Google Scholar

- Research which is freely available for redistribution

Submit your manuscript at www.biomedcentral.com/submit
C) Biomed Central 